\title{
Jean Racine et l'Orient, actes du Colloque international de Haïfa, 14-16 avril 1999, édités par Isabelle Martin et Robert Elbaz
}

\section{Chiara Rolla}

\section{(2) OpenEdition Journals \\ Edizione digitale \\ URL: https://journals.openedition.org/studifrancesi/37631 \\ DOI: 10.4000/studifrancesi.37631 \\ ISSN: 2421-5856 \\ Editore \\ Rosenberg \& Sellier}

\section{Edizione cartacea}

Data di pubblicazione: 15 décembre 2004

Paginazione: 605-606

ISSN: 0039-2944

\section{Notizia bibliografica digitale}

Chiara Rolla, «Jean Racine et I'Orient, actes du Colloque international de Haïfa, 14-16 avril 1999, édités par Isabelle Martin et Robert Elbaz», Studi Francesi [Online], 144 (XLVIII | III) | 2004, online dal 30 novembre 2015, consultato il 08 mai 2021. URL: http://journals.openedition.org/studifrancesi/37631 DOI: https://doi.org/10.4000/studifrancesi.37631

Questo documento è stato generato automaticamente il 8 mai 2021.

\section{cc) (†) $\odot$}

Studi Francesi è distribuita con Licenza Creative Commons Attribuzione - Non commerciale - Non opere derivate 4.0 Internazionale. 


\title{
Jean Racine et l'Orient, actes du Colloque international de Haïfa, 14-16 avril 1999, édités par Isabelle Martin et Robert Elbaz
}

\author{
Chiara Rolla
}

\section{NOTIZIA}

Jean Racine et l'Orient, actes du Colloque international de Haïfa, 14-16 avril 1999, édités par Isabelle MARTIN et Robert ELBAZ, Tübingen, Gunter Narr Verlag, 2003, pp. 229.

1 Il volume raccoglie gli atti del convegno tenutosi ad Haïfa nel 1999. Gli studi analizzano, nelle sue reciproche influenze, l'asse Oriente-Occidente così importante per comprendere la produzione del grande drammaturgo, soprattutto le pièces dette bibliche o, appunto, orientali. L'Oriente, in effetti, è una costante delle opere raciniane: quando non vi si svolge direttamente l'azione, esso è comunque presente attraverso personaggi protagonisti che ne sono originari. Talvolta, come mette in evidenza Alain VIALA nella Préface (pp. 7-9), l'Oriente è un universo mitico, sorta di motore dell'azione nella sua rappresentazione di un vero e proprio oggetto del desiderio.

2 Il volume è suddiviso in sei sezioni. La prima, "L'Orient grec et turc", si apre con il contributo di Pierre RONZEAUD (Entre Orient et Occident: poétique et politique de la ruse dans "Mithridate", pp. 17-32), il quale individua in Mithridate una vera e propria poetica dell'astuzia. Antoine SOARE ("Bajazet" dans l'imaginaire racinien, pp. 33-5l) studia l'uso e l'estensione della sillessi, in particolare in Bajazet. André ELIAS MAZAWI e Isabelle MARTIN ("Bajazet" en arabe: entre traduction et acculturation, pp. 53-62) analizzano l'adattamento in arabo per un pubblico medio-orientale di una pièce "mussulmana e turca" quale è Bajazet, mettendone in luce le manipolazioni di cui è stata oggetto. 
3 La seconda sezione, "Bible et poésie", contiene solo il contributo di Georges MoLINIÉ (Poéticité et négativité: Bérénice ou l'Orient saccagé (à propos de «Bérénice» I-4), pp. 65-68), il quale analizza alcuni problemi drammaturgici e poetici in Bérénice.

4 La terza parte ("Images du pouvoir”) raccoglie gli studi di Alain VIALA («L'empire de l'Asie», pp. 71-79) e Deborah BLOCKER («Esther» à la cour du roi de France: l'Orient biblique christianisé, éloge ou dénonciation?, pp. 81-103). Nel primo l'A., concentrandosi su alcuni versi in particolare, mette a nudo i meccanismi del potere e della tentazione «de l'empire de l'Asie» in Iphigénie. Esther è invece al centro dello studio della Blocker, la quale analizza, all'interno del contesto assolutista della Francia del XVII secolo, l'uso delle fonti bibliche.

5 La sezione "L'univers féminin: images de Bérénice" contiene il contributo di Denise BRAHIMI (Bérénice, Reine d'Orient, pp. 107-112), nel quale la figura mitica di Berenice viene analizzata in un'ottica femminista.

6 Lo studio di David MENDELSON (Quand Chateaubriand lisait Athalie à Jérusalem: le modèle de cette pièce à l'époque préromantique, pp. 115-132) inaugura la quinta parte ("Racine et l'Orient au delà de Racine: influences"): qui, attraverso uno sguardo più vicino a noi sia nel tempo che nello spazio, l'A. si interroga sul ruolo che la lettura di Racine ebbe sull'immagine dell'oriente che Chateaubriand si formò durante il suo viaggio a Gerusalemme. Pierre FRANTZ (Athalie au XVIII ${ }^{e}$ siècle, pp. 133-146) analizza la ricezione di Athalie, pièce sommamente religiosa, nel corso del XVIII secolo. Isabelle MARTIN ( $L a$ tragédie idéale: l'influence de J. Racine sur Sébastien Nicolas Roch Champfort, pp. 147-156) mette in luce l'influsso che ebbe Racine su Champfort, ed in particolare sulla sua tragedia Mustapha et Zéangir. Il contributo di Alexandra e Victoria DUGovsKY (Racine en Russie. L'exemple d'Athalie, pp. 157-169) evoca un altro Oriente, quello dell'ex URSS, mettendo in luce come il testo di Athalie tradotto in russo fosse stato letto e sfruttato per fini ideologici molto diversi rispetto a quelli pensati da Racine.

7 L'ultima sezione, "L'Orient et la dramaturgie", contiene tre studi. André BLANC (Vision de l'Orient chez Racine et ses illustrateurs, pp. 173-182) e François DARTOIS-LAPEYRE (Racine, l'Orient et les livrets d'opéra au XVIII et XIX siècles, pp. 183-203) rievocano il fascino orientale delle scene teatrali, delle illustrazioni, delle coreografie che accompagnavano le opere di Racine. Léon GAIGNEBET in Revoir Racine (pp. 205-207) esprime tutta la sua passione per il celebre drammaturgo e la sua ancora grandissima attualità. Chiude infatti la miscellanea una piacevolissima galleria di riproduzioni di illustrazioni d'epoca e di alcune incisioni su legno che lo stesso Gaignebet ha esposto durante una mostra che si intitolava appunto "Revoir Racine". 